\title{
On Contradictory Christology: A Reply to McCall's 'Doctrinal Orthodoxy and Philosophical Heresy’
}

\author{
Jc Beall \\ University of Connecticut
}

\section{Introduction}

Thomas McCall's paper aims to highlight issues for Contradictory Christology (and a contradictory theology, generally) from an exclusively theological - but also in some ways even pastoral - vantage point, versus from a philosophical or philosophy-driven perspective. Such a contribution is invaluable to the broad project of Contradictory Christology (theology, generally), as the position is not advanced as a 'merely philosophical' view but instead as a candidate for the theological truth of the central core of Christian thought (viz., the incarnation) and other aspects of theological reality. ${ }^{1}$

McCall's first four sections flag a variety of issues and concerns while also jointly providing a synopsis of salient ideas in the target paper 'Christ - A Contradiction'. McCall's principal section is his fifth section, which marches through four fundamental questions that confront Contradictory Christology.

The structure of this paper runs as follows. $§ 2$ briefly responds to three issues that McCall raises in his first three (largely synoptic) sections. $\S 3$, in turn, responds to McCall's concern about potential promiscuity with respect to theological contradictions. $\$ 4$ provides my first steps towards answering McCall's four principal questions for Contradictory Christology.

\section{Clarity and charity}

McCall's discussion in his $§ \S 1-3$ raises many issues, each one requiring a deeper reply than I provide here. ${ }^{2}$ In my following replies to said issues (\$§2.1-2.3) I aim towards brevity over breadth, often pointing in the direction of answers rather than providing full-on answers; and I do so all with a promise of fuller discussion in another venue.

\footnotetext{
1 A tangential, autobiographical and entirely non-substantive comment: I cannot but note that its various section titles, which one cannot help but enjoy, would've earned McCall's paper very high marks in the homiletics class I once had to take; they are 'musical' while also highly telling. (I did not do so well in that class, and do not now attempt to pull off similarly valuable section titles.)

2 The deeper reply is in the promised 'larger project' to which McCall alludes (namely, a monograph entitled The Contradictory Christ).
}

Journal of Analytic Theology, Vol. 7, June 2019

10.12978/jat.2019-7.878080798289

(c) 2019 Jc Beall • (C) 2019 Journal of Analytic Theology 


\subsection{Clarity: subclassical logic as a last resort?}

The issue at hand is one that McCall doesn't intend to use as an objection or in any way as the focus of his symposium paper. Still, the issue is worth a comment because it reflects a common attitude concerning the mainstream account of logic (-al consequence).

After noting that Contradictory Christology offers a very different view of the apparent contradiction of Christ - offers a very different solution to the fundamental 'problem' of Christology - McCall writes as follows:

I am not yet persuaded that such a move is either viable or necessary; I am not convinced that the kind of work done in analytic Christology is unsuccessful (and thus that Christians need to resort to [nonstandard accounts of logic] that call for exceptions to the law of noncontradiction). (473-474)

These remarks reflect the view that the standard account of logic is the best account of logical consequence, and hence that any nonstandard account should be adopted only if there's pressing or even desperate need to do so. Such a view, I think, should be rejected. ${ }^{3}$

This paper is not the place to rehearse independent arguments for nonclassical (in particular, subclassical) accounts of logic versus the mainstream (socalled classical) account; however, in light of McCall's remarks above, two comments might be useful.

First, while I am no historian of logic, it is pretty clear that the standard (socalled classical-logic) account was never intended to be an account of the logical consequence relation on our common language (say, English or other natural languages); rather, it was intended to model the consequence relation involved in mathematics. Mathematics is a very special phenomenon, where the extra-logical vocabulary is nearly as sparse as the logical vocabulary itself, and the vocabulary in such theories is strikingly precise - often a paradigm of precision. In standardly done mathematics, the consequence relation governing the logical vocabulary (i.e., standard first-order vocabulary) is what we now call 'classical logic'.

But now the leap: is the classical-logic account true of the broader common language - beyond the language of mathematics? This is a wide-open question! In

\footnotetext{
${ }^{3}$ I should also briefly note that, from my perspective, McCall's characterization of standard solutions to the fundamental problem of Christology (see 473) is true but possibly misleading: he claims that such 'proposals seek to show that there is no logical contradiction between the admittedly striking affirmations made by the creeds - and thus the Christology of the creeds should not be rejected on the grounds that it is necessarily false [or untrue]' (473). A theory (including a theology) can be necessarily false or untrue without being logically contradictory - that is, without containing a logical contradiction. Witness: if a theology contains 'There is no god' or 'Satan is Christ' or some such theological absurdity, the theory is necessarily false (or untrue). Ultimately, then, an avoidance of logical contradictions is not the key aim even in standard responses to the fundamental problem; it's a desideratum involved in such responses given their acceptance of the standard story of logical consequence.
} 
many ways one should find it surprising to think that the standard account, which was constructed to be an account of nothing more than the precise confines of stark but beautiful mathematics, is also the correct account of a language that contains not only very imprecise language (e.g., 'is a child' or whatnot) but downright paradoxical expressions such as 'true', 'exemplifies' and more. Furthermore, that the standard account - again, constructed to model only the consequence relation in mathematics - obviously governs the language of true theology is a view which itself requires argument, as far as I can tell. I know of no good argument that makes the case. ${ }^{4}$

The second comment is that there is a very simple argument for the view that a subclassical account of logic should be accepted over the mainstream, classical-logic account. The argument is spelled out elsewhere (Beall 2018), but the gist is simple. By accepting a subclassical account of logic (e.g., FDE) you lose no true theories (e.g., no classical-logic-governed theories) and you gain viable - and, note well, currently very much 'live-option' - candidates for true theories of especially strange phenomena (e.g., the incarnation of the transcendent god, various lesser phenomena such as semantic oddities, perhaps vague phenomena, and more). In a slogan: you lose nothin' and you gain som'in'. And that, as my grandad would say, ain't nothin'.

Exactly how it can be that the subclassical account of logic loses nothing (i.e., loses no true theories) is fairly straightforward but involves discussion that goes beyond the confines of this one. Details are given elsewhere (Beall 2018).

In the end, McCall's given autobiographical comments (above) on the lack of 'need' for a nonclassical (especially FDE) account of logical consequence reflect a common view that, I think, is not well-founded. McCall is abundantly clear that he offers such comments only to put his own cards on the table, so to speak, and not at all to object to a nonclassical account of logic. Still, I hope that the few remarks above give pause on whether the mainstream account of logic is in fact one to which we all should so firmly cling as the top candidate. To repeat: I know of no good argument that supports the view that the correct account of mathematical consequence is thereby (because the right account of consequence in true maths) the correct account of consequence in all true theories (including the radically strange ones like true theology); and there is a good argument for accepting a subclassical account over the standard one.

\subsection{Technical point: 'theological truths of relevance'}

Another noteworthy issue that McCall raises (in passing) concerns the full reach of consequences that a complete-as-possible theology contains. In describing my view of the role of logic in theology, McCall writes as follows:

${ }^{4}$ One argument might be that the account gets consequence for mathematics right; and mathematics is powerful and beautiful and an exemplar of fundamental theory; and since theology is equally powerful and beautiful and an exemplar of fundamental theory, it too ought to be governed by the consequence relation of mathematics. (I leave the fate of this argument for reflection.) 
[According to Beall] 'theologians must not only add various basic truths about God but also 'complete' (as far as possible) the theory via a consequence relation' [Beall, 'Christ - A Contradiction', 404]. Accordingly, theologians should include in their theories not only those truths that they take to be revealed by God but also what truths of theological relevance really follow from those revealed truths. (474, italics mine)

The issue to which I should briefly reply arises in McCall's footnote 1 immediately following the above quotation:

I say 'what truths of theological relevance' because I think that Beall's way of putting matters commits us to too much. Every necessary truth follows from any truth, but surely systematic theology shouldn't have to include all of that to be complete. The task of systematic theology is daunting enough - and the textbooks long enough - without also having to include 'God is triune and $2+2=4$ ' and 'God is triune or $2+2=4$.' (474475 , fn 1 , italics mine)

By way of clarification I note that even if systematic theology shouldn't have to include all necessary truths expressible in the language of the theory (viz., theology), it just does - full stop, provided that it is closed under a consequence (entailment) relation. The consequence relation (qua closure relation), being an absence-ofcounterexample relation, puts all necessary claims (in the language of the theory) into the theory, and does this regardless of the theologian's wishes. So, all such necessary truths - whether irrelevant or otherwise - are in the theory, regardless of whether the theologian actually writes them down on paper. Accordingly, such truths do not increase the workload of the systematic theologian.

Moreover, and still just by way of clarification, whether the sentence 'God is triune or $2+2=4$ ' (or the like) is in the true theology depends in part on whether the language of (true) theology contains the language of arithmetic - indeed, includes, as a non-theological true sub-theory, true arithmetic. I do not have a firm view on this except to say that if the true theology does not contain the language of arithmetic then McCall's example (involving ' $2+2=4$ ') requires revision. The same goes, of course, for the languages of other true theories.

\subsection{Charity and Pawl's good news about consistency}

In 'Christ - A Contradiction' I consider an objection inspired by Timothy Pawl's hermeneutical argument for a non-contradictory Christology. Pawl's argument, in short, is simply that it would be uncharitable to attribute contradictions to the conciliar fathers - to the writers of conciliar texts, including those from Chalcedon. By way of reply I argue in 'Christ - A Contradiction' that, contrary to Pawl, the more charitable reading is the contradictory one; otherwise, the conciliar fathers left the glaring appearance of a contradictory Christ shining through without so much as 
flagging that the predicates in question (viz., the fundamental-problem predicates such as 'mutable' and 'immutable' etc.) are being used in nonstandard ways - namely, in ways that, given Pawl's good news conveyed in his target monograph (Pawl 2016), take away even the slightest hint of contradiction.

In his 'Explosive Theology' (440-451) Pawl replies to my argument above, and argues that at best the jury should remain out on whether the Pawline (noncontradictory) or my own (contradictory) reading of the given texts is the more charitable of the two. In my reply to Pawl's given reply (452-472), I concede the point: more needs to be studied and explored. As things stand, I remain unconvinced that Pawl's reading is more charitable than mine - nor, as things stand, mine more than his. As things stand.

McCall's $\S 3$ wades into the foregoing issue on charitable readings of the creeds. Contrary to his own assessment, nothing that McCall argues convinces me that Pawl's reading - and Pawl's solution to the fundamental problem - is the more charitable (let alone more plausible) Christology. I remain as per above: the jury remains open. Still, it may be useful to comment on a few key remarks that McCall's discussion makes on the topic. ${ }^{5}$

The main issue that requires comment is McCall's appeal to various expert claims on the historic place of inconsistent, contradictory or, as I think is at issue, explosive (or otherwise theoretically absurd) claims in the history of philosophy and in theology. On the former (viz., philosophy) McCall quotes from an early authoritative work by Brandom and Rescher (1979):

Since Aristotle's day, virtually all logicians and logically concerned philosophers in the mainstream Western tradition have had a phobia of inconsistency. They have been near to unanimous in proscribing it from the precincts of their logical and ontological theorizing, holding that the toleration of inconsistencies would inevitably bring cognitive disaster in its wake. (477)

Of course, Brandom and Rescher think that such widespread fleeing from inconsistency is unwarranted unless, of course, the inconsistency takes the form of an explosive sentence, one which genuinely entails all sentences in the language of a given theory. Their book goes on to give elementary models of consequence relations that are not explosive with respect to contradictions, even though such consequence relations might explode with respect to various theory-specific sentences. (Worth

\footnotetext{
${ }^{5}$ I also wish to note that I share McCall's enthusiastic embrace of the Coakley-inspired take on creedal statements (see McCall's §3), at least as far as McCall goes with them:

[I]t is much better to think of the creedal statements as both making central affirmations ('here is what we must hold') and crucial denials ('here is what we can't believe') - and then as leaving interpretive space for various possibilities and metaphysical development between the core of what we must hold and the boundaries beyond which we cannot go. (476)

This is completely compatible with a Contradictory Christology - and contradictory theology, generally - which, I take it, is McCall's point (even if Coakley herself might be pressing against a contradictory theology in my sense).
} 
noting too is that the 'phobia' of which they speak, which has led to near unanimity 'in proscribing [inconsistency] from...theorizing' is compatible with my view according to which logical consequence allows for gluts while many true theories rule them out (in addition to ruling out theory-specific absurdities).) On all of this, I agree: the history of mainstream theorizing has reflected a largely unreflective stance on contradictions, based largely (I surmise) on a rather normal diet of examples.

And on a similar 'phobia' against inconsistency in theology McCall quotes Radner 2016:

Almost all the Fathers were wary of affirming that Scripture had within itself real 'contradictions', a charge associated with the enemies of Scripture. And much effort was made to explain the presence of such apparent tensions within the texts. (477)

Worth flagging here is that pending Radner's definition of 'real contradictions' this passage is not terribly telling on the issue of whether contradictions (i.e., sentences of the form $! A$ ) are problematic. I suspect that, probably saddled with the standard account of logic (which, as in $§ 2.1$, was constructed as a model of consequence in mathematics and nothing more), Radner's use of 'real contradiction' is intended to be equivalent to 'explosive sentence', where Radner would (given the standard conception of logic) treat contradictions as among the real contradictions - the explosive sentences.

The pressing question, to my mind, is not whether many theologians and philosophers are under the grip of the standard account of logic (-al consequence); the important question is whether they ought to be. Why hold that account? As above (see §2.1), I see no good reason for it, and some good reason against it. But I've said enough on that topic for present purposes. We know that the vast majority of thinkers at one time treated 'round earthers' (or take some other such widespread erroneous belief) as enemies of knowledge; but a widespread - indeed, near unanimous phobia - against a certain claim does not show that the claim is untrue. McCall, of course, does not in any way (whatsoever) suggest otherwise; but it is worth remembering that widespread - even near-unanimous (even unanimous) - belief can be untrue.

McCall's point in quoting the above passages, part of his larger argument on the plausibility of a noncontradictory Christology over a contradictory one, is that, given the widespread fleeing from contradictions, it is uncharitable to infer contradictory readings of the given theological creeds. I remain unconvinced by this if, as I believe, a central part of charity aims for truth over what may've been fallacious intentions - based on erroneous beliefs - of the authors. (A charitable reading, on this view, can go against the intentions of the text's authors.)

\section{Rarity and the threat of promiscuity}

Contradictory Christology, as developed so far, is conservative with respect to the stock of true contradictions. In short, the account, as so far developed, contains only 
contradictions that follow from the core contradiction of Christian theology: namely, Christ's contradictory being emerging from the union of two contradictory natures (where two natures are contradictory iff their joint exemplification entails a contradiction). This is at the very core of Christian thought; it is at the very heart of Christian theology, separating it not only from its monotheistic cousins (including Judaism and Islam) but also from the many historical heresies that attempt to navigate around the apparent contradiction. While there may be other true contradictions in theology that are not entailments from the contradiction of Christ, my official account, as developed so far, refrains from endorsing as much. Those issues are for further study, reflection, and debate.

McCall firmly understands the conservativeness of my account with respect to true theological contradictions. But he worries that theologians more generally will reject such conservativeness in a promiscuous pursuit of contradictory mayhem. As he puts it (n.b.: I insert bracketed numerals for ease of reference):

I worry that many theologians will indeed take what Beall says as [i] open season on the constraints of classical logic and, more importantly, [ii] to license contradictions galore.... [McCall footnotes a work of Ephraim Radner who discusses examples of potential such 'threats'.] (478)

As for (i), and as per §2.1, I think that it is - or at least should be - 'open season' on classical logic as an account of logic (-al consequence); but with McCall I also see no reason to think that the constraints of so-called classical logic - in the form of extralogical, theory-specific constraints on the consequence relations of many true theories - should be rejected. And as for (ii), nothing I have said provides good reason to accept that theological truth or the truth of any other part of reality is rife with contradictions.

McCall is aware of my position on (i) and (ii) but his worry persists:

It is not hard to imagine a theologian being convinced by Beall and then saying, 'Cool, I no longer need to worry about avoiding contradictions.' Beall might remonstrate with 'No, you theologians should not seek out contradiction!'. ... But the theologian's response is quick: 'look, we don't have to seek them out - they are all over the place and come looking for us. They are unavoidable. The good news now is that we don't need to worry about them.' (478)

How to reply?

Let me be clear that I defer to McCall's sense of the general proclivities of contemporary theologians. My experience with systematic theologians does not raise the worry that McCall carries; but I gather from McCall's expressed concern that my experience is based on non-representative examples. The question remains: how to respond?

McCall acknowledges that one who advances a theological position cannot control the use to which it will be put by other theologians. Still, his concern reflects 
the need to be even clearer about the irresponsibility involved in making the leap from some true theological contradictions to many. The imagined response, per McCall's passage above, is that such a so-called leap is in fact very well warranted by the apparent ubiquity of contradictions in theology - from God's too-heavy stone to the core Trinitarian doctrine to God's contradictory knowledge of the claim 'God cannot know this sentence' to so much more. Far from a paucity of apparent contradictions theology is a cacophonous carousel of core contradictory creeds.

No it isn't. That's my reply: no, theology is plainly contradictory at just one core point - the incarnation. Yes, the omni-god problems need to be addressed, but the only point at which apparently contradictory predicates are explicitly attributed in core theology is Christ's two-natured being - as the fundamental problem attests. ${ }^{6}$ The would-be contradictions involved in God's omni- properties are fairly downstream, whereas the apparent contradiction of Christ's 2-natured being hits the moment one looks at the water. Similarly with the Trinity, which is a core axiom of Christian theology but which carries the hint of contradiction only if one thinks - for what reason? - that the identity relation involved in the axiom is an equivalence relation (or sanctions substitutivity of 'identicals' so understood)? One reason to think as much is to think that logic itself provides an identity relation which is common throughout all true theories, and that that (alleged) relation is an equivalence relation or at least sanctions substitutivity of 'identicals'. By my lights, that's a mistaken view. But even if such a view were correct, there's no good reason, as far as I can tell, to think that the identity relation involved in the Trinitarian axiom is the relation that logic itself (supposedly) supplies to all true theories. ${ }^{7}$

I take McCall's concern very seriously. His aim is to aid in the further development and articulation of Contradictory Christology, but do so in a way that is sensitive to its reception by practicing theologians. On this score, I hope to be clearer than crystal: there may be true contradictions beyond the core contradiction who is Christ; but a giddy quest for making Christianity contradictory at every whim is not only (to use McCall's term) promiscuous; it is simply silly, irresponsible 'theorizing' which, pending good reason to think otherwise, would appear to me to not be after truth at all.

\section{Responses to McCall's principal questions}

McCall's paper raises four fundamental questions for the (as yet nascent) contradictory Christian theology that I've advanced. The questions are invaluable for

\footnotetext{
${ }^{6}$ Note that gappy responses to the standard omni-god problems are available where no such gappy solution is available to the apparent contradiction of Christ - inasmuch as the fundamental-problem predicates are definitive (axiomatic) of Christ, and so can be gappy only at the cost of heresy. (See, e.g., McCall's echoing of Coakley about the role of the creeds in constraining what true Christian theology must contain.)

${ }^{7}$ Van Inwagen's pioneering paper on so-called relative identity relations (1988) is in keeping with my view of identity relations in theories: the theorist needs to supply her identity relation, which mightn't be an equivalence relation, or mightn't validate (by the lights of the theory's entailment relation) substitution of 'identicals'. See too the earlier work of A. P. Martinich (1978).
} 
progress on the fuller account. In what follows I simply rehearse the question (as concisely as possible) and in turn provide a response (again, as concisely as I can compatible with clarity).

\subsection{Epistemology: Which contradictions are true?}

McCall puts his first question just so:

[H] ow are we to know which are the 'true' contradictions and which are the false? The theologian who makes do with the shop-worn old tools of classical logic and theology has a ready and easy answer: there are no 'true' contradictions. (479)

This is clearly a fundamental question.

Before addressing the fundamental epistemological question a clarification about true 'versus' false contradictions should be flagged. ${ }^{8}$ For convenience, let $! A$ be $A \wedge \neg A$ (with parentheses around it when necessary). On my view, reflected in the truth and falsity conditions for logical negation (and logical nullation, though this is logically redundant), any true contradiction is a false contradiction: ! $A$ is true just if $\neg ! A$ is true too. Put in terms of true theories, a true theory contains an application of logic's truth operator (viz., $\dagger$ ) to a contradiction $A$ just when it contains an application of logic's falsity operator (viz., $\neg$ ) to $! A$ too - that is, $\dagger ! A$ is in a true theory just when $\neg ! A$ is in the true theory too. So, if we have a true contradiction, we thereby have a false contradiction too.

McCall's question, in light of the terminological clarification above, is really just this: which are the true contradictions? The answer, to the frustration of truthseeking theorists everywhere, is the usual one: namely, that's the question we're all trying to answer.

Take a step back to the general question of which McCall's is a special instance: namely, which are the true sentences? If there were a simple answer to this question prior to arrival at the answer, our search for truth would be very much easier than it is - to put things mildly. Indeed, even if there were a complicated but largely algorithmic answer to this question, our search for truth would be vastly easier than it is. But such is not the way things are. Sorting the truths from the rest is a messy and very, very difficult business, one still nicely illustrated by the old metaphor of rebuilding our raft at sea. Accordingly, there is no simple answer to the general form of McCall's question - an answer to which would sort all truths from the rest.

Of course, McCall's question is explicitly not the general one; it concerns only contradictions. And in that case - the case of contradictions - one might suggest that there ought to be a simple answer. But why? Consider the same question concerning 'ought' sentences: which of them are the true ones? Or 'it is necessary that ...'

\footnotetext{
${ }^{8}$ I should also note that I am unclear on why McCall uses scare quotes around 'true' in the context. My position is not that there's some special sense of 'true' - say, true* - whereby some contradictions are true*. My position is that some contradictions are true - full stop - in the usual sense of 'true'.
} 
sentences: which of them are the true ones? And so on for any form of sentence: which of them are true? Truth-seeking inquiry is complicated precisely because there simply isn't an easy answer to such questions.

But one might still press the particular example to which McCall points: namely, contradictions. As McCall rightly says, if we adopt the mainstream theory of logical consequence (viz., so-called classical logic) we get an easy answer to at least that question (of contradictions): namely, none of 'em - full stop. But getting an easy answer to the given question is not itself good reason to accept the easy-answergiving theory. If it were, we'd have good reason to accept the trivial theory of every phenomenon. ${ }^{9}$ After all, trivialism gives the easiest answer to figuring out the truths: namely, all of 'em.

McCall is correct that on my account logic does not help with respect to sorting truths of the form ! $A$ any more than logic helps with sorting truths of the dual form ${ }_{\mathrm{i}} A$ (where $\mathrm{i} A$ is $\neg A \vee A$ ). In this respect, my account makes our epistemological situation with respect to such sentences appear to be more difficult than the standard account of logic affords. But if my account is correct, our epistemological situation was always just that difficult: it wasn't logic classifying $! A$ as logically false or $i A$ as logically true; it was our extralogical theorizing, perhaps backed by various methodological practices (with respect to default rejection of $! A$ and/or default acceptance of $; A$ ) that did the given epistemological work. For all that I can see, few if any of such practices are jeopardized by an account according to which there is a strikingly rare contradictory being.

But one might still press: but if we accept the existence of even one contradictory being - regardless of how strikingly radical, strikingly bizarre, and strikingly abnormal the being appears to be - we are no longer justified in a default rejection of contradictory accounts of any other being.

No. This paper is not the place to take up such a huge epistemological issue. (And, alas, probably the promised larger book project is not the place either.) But let me reply as clearly and concisely as I can: such a charge is untrue. To put my epistemological cards on the table: I accept a rather crude form of so-called epistemic conservatism according to which we are justified in what we accept unless we have some special reason to reject it. (This is the sort of dual of a crude Cartesian foundationalism, according to which we are unjustified in what we accept unless we have some special reason to accept it.) For all that I can tell, the history of truthseeking disciplines, aimed mostly at the normal diet of examples, has run smoothly and successfully on a default rejection of gluts (and likewise gaps). Things have not gone so well when it comes to the bizarre phenomena that appear to all reflective lights to be wildly paradoxical, paranormal, and equally beyond the normal run of examples. Such phenomena scream out against our normal - indeed, widely default extra-logical practices of acceptance-rejection behavior. But further details of such difficult epistemological and methodological issues must wait for elsewhere.

* Tangential and long parenthetical remark. I want to briefly flag that the epistemological issues that McCall is raising for my contradictory theology are at least equally - in fact, more - problematic on the Pawline (or Biel) sort of view that McCall

\footnotetext{
${ }^{9}$ The trivial theory in/for a language $L$ is the theory containing all sentences of $L$.
} 
claims is not implausible (see 478 , ultimate paragraph of $\S 3$ ). On my view, logic does not decide the question of whether arbitrary contradictions are true, false, gappy or glutty. We, qua theorists, have to do that. But on my view the standard truth/falsity conditions of contradictions - and the standard satisfaction conditions of all fundamental-problem predicates, and all predicates in general - are preserved. And while on Pawl's view logic does decide the status of all contradictions (viz., they're one and all just-false), much of the remaining language - including all seemingly 'explosive pairs of predicates' - is unhinged from even the possibility of explosion. Let me briefly explain. On Pawl's account, nonstandard satisfaction conditions for 'mutable' and 'immutable' (and likewise for all fundamental-problem predicates) are given, wiping away even the appearance of contradiction. Briefly, to get a sense of the Pawline-cum-Biel solution, consider the Scotus-inspired example:

1. $x$ is blind.

2. Therefore, it's false that $x$ can see.

Pawl's endorsement of a Scotus passage (Pawl 2016,158, citing work of Richard Cross) suggests that the Pawl solution rejects the entailment from (1) to (2). The problem with the alleged entailment, according to Pawl ('s given endorsement of Scotus), is that $x$ might have some 'part' (not necessarily mereologically understood) that allows - indeed, might itself essentially entail - seeing.

Here's the rub: To avoid worries of ad hocery Pawl likely extends such treatment to all predicates, not just the ones that would otherwise cause problems. But, then, it looks like this licenses far too much. Let M (for you know whom) be the unique (twonatured) Round Square - which is round (in virtue of its Circular nature) and Square (in virtue of its 4-right-angled nature). On what grounds do we now argue that there is no object M? Here's one obvious and very mainstream argument from reductio.

3. $M$ is Round and M is Square.

4. $\quad$ M is Round. [(3), Simplification]

5. Therefore, $M$ is not Square (i.e., it's false that $M$ is Square). [(4) and the alleged entailment from Round to not-Square]

6. Therefore, M is Square and not Square. [(3) and (5)]

7. Therefore, ... whatever nightmare sentence you like... [by a bad view of logic, but let this pass.]

We're to conclude that there's no such object as M - no Round Square. But, of course, the argument from (4)-(5) is unavailable if the entailment from (1) to (2) fails. But if that's unavailable, what rules out Round Square (or replace any would-be incompatible predicates $\mathrm{F}$ and $\mathrm{G})$ ?

Now repeat McCall's epistemological worry: how are we to know the incompatible pairs of predicates from the compatible ones?

The point, for present purposes, is that McCall's epistemological worries may be even more severe for the sort of noncontradictory 'eking-out' solutions that McCall thinks are more plausible than contradictory candidates. I flag this not to endorse the sketched objection to Pawl's (Biel's) account, or to go into further detail; I flag the 
issue simply to emphasize that the epistemological issues to which McCall points are not a peculiar problem for a Contradictory Christology - and, as said, there may be a greater problem for leading noncontradictory candidates. (The larger monograph project is intended to discuss Pawl's views, along with other noncontradictory views, in much more detail.) * End long parenthetical remark.

\subsection{Epistemology: What level of support is required?}

McCall puts his second question as follows:

A second question is closely related to the first: what is the level of required support that is needed to establish the truth of both claims of a contradiction? (479)

My reply to the question, as it stands, is straightforward: one needs the support that shows them to be true. What is that? Again, as in §4.1, the standards of truth are what they are; and the difficulties of our epistemic position with respect to finding truth are also what they are - typically, very difficult. The bar of truth does not discriminate among candidates: for a sentence - no matter what it is - to be true is, well, for it to be true. Put 'graphically', the truth of

'Snow is white' is true

requires nothing more nor less than that snow is white. Likewise, the truth of

The consequence relation for metaphysical necessity is so-called S5

requires nothing more nor less than that the true theory of metaphysical necessity (whatever that is) be closed under the so-called S5 consequence relation. Likewise, the truth of

It's false that Christ is mutable

requires nothing more nor less than that it's false that Christ is mutable. And yet again likewise, the truth of

It's true that Christ is mutable

requires nothing more nor less than that it's true that Christ is mutable. And so on, including logical conjunctions of such claims. In particular, the truth of

It's false that Christ is mutable and it's true that Christ is mutable

requires nothing more nor less than what is required for the truth of the respective conjuncts. 
As stated, McCall's question is answered as above. But McCall is in fact after more, where the more is expressed in three more questions as follows (each taken verbatim from 479-480).

* McCall's three supplementary questions:

1. If two theological propositions taken together seem to produce a contradiction, does that give us reason to go back and look closely at the data or evidence (whether textual, empirical, experiential or just what) supporting the propositions?

2. If another non-contradictory theory is not impossible and also makes more-or-less adequate sense of the data, is that one to enjoy a preference (at least initially)? If so, then why?

3. Just how much support for the propositions must one have to embrace something that surely is an actual contradiction?

McCall is very clear that these questions are not highlighted as flaws of omission in my target paper 'Christ - A Contradiction'. The three given questions are highlighted because 'at some point answers to such questions will be important if [Beall's] proposal is to put down theological roots and produce some doctrinal fruit' (480).

By way of reply I offer the following as directions towards answers, not as fully developed answers to McCall's given questions.

- Reply to (1): it depends on what 'seems' means here. Take the fundamental problem itself. Here, the central truths of Christ, as recorded in Chalcedon and creeds, screamingly seem to be contradictory - right on its surface, right from the get-go. And yet, even with their screaming contradictoriness, they stand as defining truth. Given the centrality of the apparent contradictoriness of such (fundamental-problem) truths, going back to 'eke out' a non-contradictory substitute strikes me as misguided, or at least without good reason. ${ }^{10}$ But if 'seems' in McCall's question flags that we are talking about more tenuous, less central facets of theology than the apparent contradiction of Christ displayed on the very welcome sign of Chalcedon-constrained Christology, then following the normal default rejection of a contradictory conclusion is probably reasonable. (I say 'probably' because, of course, details really do matter in these sorts of what-do-I-do-here sort of question.) Again, the search for truth is hard no matter the area. Theology, as McCall reminds, is certainly no different. But the bar, as in $\$ 4.1$, is the same throughout: the support required for the truth of $A$ is, well, whatever is sufficient for $A$ 's truth. Unlike separating sheep from goats, there is no general recipe that one can follow to separate the truths from the untruths. There are simply general rules of epistemic responsibility, including think carefully; be as unbiased as you can in the

10 The 'eke out' terminology is from Coakley 2002, quoted by McCall in a different dialectical context of his paper. 
pursuit of truth; be open but not hoodwinked by inspiration (e.g., revelation); and many other general (but imprecise) such rules.

- Reply to (2): I take this question as follows. Suppose that we have a contradictory theory and a non-contradictory theory as theoretically possible candidates for the truth of a given phenomenon. (In other words, from our current epistemic position, the logical possibility of a glutty theory of the phenomenon is not ruled out.) Moreover, suppose that both candidates make equally good sense of the phenomenon (or the data concerning the phenomenon as the target of our theory). Does the noncontradictory theory enjoy some higher level of probability?

The answer to the question depends a little bit on the space of possibilities in question. If the space is equally (or even roughly equally) divided between glutty candidates and non-glutty candidates, the answer to the question is negative. If, on the other hand, the space has just a few glutty candidates compared with a vast multitude of non-glutty candidates, then the answer is affirmative. Pending details, there is not a lot more to say by way of answer.

- Reply to (3): This question is answered in $§ 4.1$ above.

Even though (3), as above, is answered in $§ 4.1$ it is worth repeating that we do seem to have a longstanding successful practice of rejecting logic's glutty possibilities as leading candidates for the truth of a phenomenon. The practice revolves around 'normal cases', things that offer up little suggestion of being glutty (or gappy). If, at bottom, McCall's epistemological questions are fueled by the practical question of whether we should continue the given default methodological practice with respect to gluts (and/or gaps), my reply is: yes. And if one asks whether the 'yes' here is defeasible the answer is: yes. After all, we are not only in a difficult epistemic situation with respect to finding truth; we are also epistemically fallible through and through. The existence of true contradictions (gluts) neither helps nor hurts our epistemic predicament, as far as I can see. Those who, perhaps with McCall, think that the logical possibility of gluts (or gaps) wreaks havoc on our pursuit of truth are mistaken, as far as I can see. The chief effect of such logical possibilities is not havoc; the effect is simply that logic itself no longer explains our default practice of rejecting gluts (gaps). By my lights, this is not a negative effect.

\subsection{Theology and metaphysics: what of modality?}

McCall puts his third principal question as follows:

A third question ... is this: how does Beall's proposal map onto issues of modality? (480)

The reply to McCall's question, stated just so, is that the true theory of modality (for every modality there is) is underwritten by logical consequence (viz., FDE, according 
to me): the true theory has, as the consequence relation governing just the logical vocabulary, the given subclassical consequence relation.

But there are background concerns driving McCall's question, ones that aren't addressed by the answer given above. By way of elaborating the driving concerns behind his third question McCall points to a dilemma around the following claim (480):

TNT: It is possible that there is at least one true contradiction and it is not possible that there is at least one true contradiction.

McCall assumes that (TNT) is either true or false - ergo, a gappy (TNT) is ruled out. In turn, McCall argues that if true then (TNT) forces a 'modal collapse' of notions that are importantly distinct in true theology, including a collapse of impossibility and necessity, necessary truth and necessary falsehood, and perhaps more. In turn again, McCall argues that if false then Contradictory Christology is either arbitrary or ad hoc in treating (TNT) as false. The (alleged) dilemma, then, is that Contradictory Christology, as I've advanced it (in concert with the given subclassical logic), is either not theologically viable (because it can't accommodate important modal distinctions) or is ad hoc with respect to modal truths - for example, the negation of (TNT) - that are important in theology (because it has no principled grounds on which to establish such truths).

A few points of reply. The first is that the true account of modality might well involve some fairly far-out 'worlds' where things behave wildly different from the S5like setting in the background of McCall's discussion. I am not suggesting that the true account of modality has such wildly far-out elements; but it may. But for present purposes I grant that something in the vicinity of S5 - modulo effects of FDE as logic - is roughly correct for some important notions of modality that are central to theology. ${ }^{11}$

11 Technical Note (for those familiar with the slate of so-called normal modal logics): if one uses the standard truth- and falsity- (at-a-point) conditions for the box and diamond, namely, where $\vDash_{1}$ and $\vDash_{0}$ are the truth-at-a-point and falsity-at-a-point relations, respectively,

- $\quad w \vDash_{1} \square A$ iff all $w$-accessible points (i.e., all $w^{\prime}$ st $w R w$ ) are st $w^{\prime} \vDash_{1} A$

- $\quad w \vDash_{0} \square A$ iff some $w$-accessible point is st $w^{\prime} \vDash_{0} A$

- $\quad w \vDash_{1} \diamond A$ iff some $w$-accessible point is st $w^{\prime} \vDash_{1} A$

- $\quad w \vDash_{0} \diamond A$ iff all $w$-accessible points are st $w^{\prime} \vDash_{0} A$

and if one puts the usual S5 constraints on the accessibility relation $R$ (viz., it's an equivalence relation on the points) and imposes no constraints on the 'worlds' - for example, allows worlds to be as glutty or gappy as logic itself (qua FDE) allows - then because there are no logical truths (no truths that are true at all of logic's possibilities) there will be no 'M-logical truths' - i.e., no M-valid sentences (i.e., sentences true at every point of every model) - either. But one still validates the characteristic S5 entailment (just not the material implication version) in such a setting: namely,

$\diamond A \vdash_{M} \square \diamond A$

where $\vdash_{M}$ is the consequence relation of the given theory of modality. [Proof: suppose $w \vDash_{1} \diamond A$, in which case there's some point $w^{\prime}$ such that (st) $w R w^{\prime}$ and $w^{\prime} \vDash_{1} A$. Since, by stipulation on $R$ (viz., the S5 requirement that $R$ be an equivalence relation), $w^{\prime} R w^{\prime}$, we have that $w^{\prime} \vDash_{1} \diamond A$. Suppose, for reductio (we're working in a set theory which rules out gluts), that $w \not w_{1} \square \diamond A$, in which case there's some point $w^{\prime \prime}$ st $w R w^{\prime \prime}$ but $w^{\prime \prime} \not \neq_{1} \diamond A$, in which case there's no point $x$ st $w^{\prime \prime} R x$ and $x \vDash_{1} A$. But $w^{\prime}$ itself 
The second point of reply is that McCall's assumption that (TNT) is either true or false is not itself logically backed, that is, it is not forced by logic (viz., FDE). Still, I see no obvious reason to reject the default rejection of gaps in this case, and in any event accept that it is either true or false (for some theologically important notion of possibility).

The third reply is the critical one: namely, that McCall's dilemma is at most an apparent dilemma; the second horn (concerning falsity) turns on a terminological issue about which 'Christ - A Contradiction' was (I gather) insufficiently clear. ${ }^{12}$ The issue concerns my use of 'logic' in discussion of Contradictory Christology (or other candidates for true theories) and the very standard use of 'modal logic' (and in particular, the use of 'logic' in 'modal logic'). I say that, where 'logic' picks out logical consequence, logic - by itself (i.e., without help from extra-logical, theory-specific principles etc.) - doesn't decide whether a contradiction is true, false, gappy or whatnot; a fortiori, logic - by itself - doesn't decide whether (TNT) itself is true, false, gappy or whatnot. McCall's second horn involves the assumption that so-called modal logic is logic; and hence, applying what I say about logic, McCall concludes that modal logic doesn't decide whether a contradiction is true, false, gappy or whatnot - and, a fortiori, doesn't decide whether (TNT) is true, false, gappy or whatnot. But - and here is where the second horn comes to a point - (TNT), McCall rightly notes, is surely decided by modal logic if anything. And if that's right, and modal logic doesn't decide the status of (TNT) because logic (hence, modal logic) doesn't decide the status of (TNT), there's nothing but ad hocery or arbitrary fiat to decide (TNT); and any theology (or theory of modality) saddled by such ad hocery should be rejected.

The problem with McCall's second-horn argument is its assumption that what's true of logic (-al consequence) is true of modal logic. As I say elsewhere (Beall and Burgess 2017; Beall 2018) the term 'logic' is used in many ways by many people. ${ }^{13}$ Moreover, the common practice in philosophy (and, to some degree, in mathematics) is to count any relation that remotely looks like a formal consequence relation, whether defined proof-theoretically or model-theoretically (which are the two main strategies for defining such relations), as 'a logic'. There's no fruit in debating such usage; it's just usage, and makes sense in the general contexts in which the terminology is used. But there are very important contexts in which a different usage is clearly in play. In particular, when the debate is whether logic is subclassical the debate is not whether the field of logic includes so-called subclassical logics. (It does, many many times over.) The debate is over which such candidate, among the many consequence relations out there, plays a particular role. Which role? My answer is the one to which 'Christ - A Contradiction' points: namely, the role of 'universal

(via $R$ 's equivalence-relation properties) is such an $x$. QED] For basic details, see Beall and Logan 2017; for more in-depth details, see Priest 2008.

12 My pointing only to McCall's second horn should not be read as my endorsing his argument for the first horn; the soundness of that argument is not clear to me (though this is not in any way a polite implicature to the effect that I think the argument is unsound). What is abundantly clear is that McCall's first horn shows why, as he rightly insists, the development of Contradictory Christology must be explicit about the details of theologically relevant modal notions.

${ }^{13}$ For an overview of the five main - and in many ways very different - subfields of logic qua discipline see my essay with John P. Burgess in the Oxford Bibliographies series (2017). 
closure' for all of our true theories. That relation, I say, governs the standard stock of first-order vocabulary that usually gets to be called 'logical vocabulary'. The usual stock (sans identity, functions signs) is involved in all of our true theories - even ones that have no modal vocabulary (e.g., arithmetic, etc.). The debate is whether that relation - governing said vocabulary - is per the mainstream, so-called classical account or whether it's nonclassical in some fashion (in my case, subclassical).

Given the foregoing usage, so-called modal logic is so called not because it's logic (in the target, much narrower sense involved in debates over whether logical consequence is subclassical); it's so called because it's an account of the formal consequence relation underwriting our true theory of the given modal notions. One such account (viz., S5) claims that the true theory of the given modal notions has a consequence relation that validates the entailment from $\diamond A$ to $\square \diamond A$. Other accounts (still in the so-called normal modal accounts) claim that the true theory of the given modal notions has a consequence relation that does not validate the given S5 entailment, but rather is weaker than S5. ${ }^{14}$ Accordingly, our so-called modal logic qua account of the consequence relation underwriting the true theory of (the given) modality - will decide the fate of McCall's (TNT), largely as a reflection of whatever's true of the given modal notions. Logic itself (i.e., logical consequence, not the extralogical consequence relation involved in the true theory of modality) will not decide that issue.

McCall's second-horn argument assumes that modal logic is as neutral on gluts as logic itself. I reject that assumption, just as I reject it for 'theological logic' - that is, the consequence relation governing the true theology. Theology itself takes a stand on whether Christ is contradictory. Logic won't dictate as much one way or the other; but 'theological logic' - qua extra-logical consequence relation involved in the true theory of theological reality - will certainly reflect the fate of gluts (similarly gaps) in the theory.

\subsection{Practical theology: what guidance for the church?}

McCall puts his fourth and final principal question as follows:

A fourth and final question is more directly practical and even pastoral in nature.... The question is: how is the account [of a contradictory theology] drawn here to offer helpful practical guidance for Christian communities if it is affirmed and applied more broadly? (482-483)

Elaborating on the question McCall writes:

\footnotetext{
${ }^{14}$ And in many so-called non-normal modal logics the behavior of modal operators fails to validate the 'meta rule' of necessitation, which says that if $A$ is M-valid (i.e., true in all models involved in the definition of the given consequence relation) then so too is $\square A$ (i.e., it is $\mathrm{M}$-valid too). The normal modal logics, by definition, validate necessitation; the non-normal ones don't.
} 
Doctrine plays important roles in the formation of the community of faith and in the formation of character and the virtues within that faith community. [McCall cites Charry 1997 as an example.] Will the acceptance of contradictions (in this case of the doctrine of the incarnation, at the very heart of the Christian fath, but potentially more broadly as well) actually strengthen the faith of the faithful and assist ecclesial communities in the important work in moral and spiritual formation? Or might it bring harm? (483)

Illustrating some potential harm that a contradictory theology - indeed, Contradictory Christology (viz., 'at the very heart of the Christian faith') - may carry, McCall presents a scenario in which Catholic leaders assemble top-shelf scholars to evaluate the ordination of women in the priesthood. Lacking no resources accessible to humans, and lacking no time to figure out the issue, the given leaders come to the following position: namely, that both of the statements

- It is true that ordination should be open to women.

- It is false that ordination should be open to women.

enjoy seemingly sound theological arguments. But since sound arguments have true conclusions the sound arguments for both (contradictory) conclusions jointly (logically) entail a contradiction. What to do? A scholar in the gathering points to the fact that logic itself, being FDE, doesn't rule out the veridicality of the given appearance. Pending some special reason to reject the strong appearance of soundness in both cases, the gathering of scholars and Church leaders proffers a unanimous statement to the effect that the given contradiction is true; and the Catholic church in turn declares the matter to be fact (dropping the modal 'should' to the actual 'is'):

- It is true that ordination is open to women.

- It is false that ordination is open to women.

Catholics are thereby required to abide by the moral and ecclesiastical obligations that follow from the truth of both conjuncts.

The point of McCall's scenario is to highlight what he perceives as potential harm flowing from a contradictory theology into the moral obligations of a church (both leaders and laity). By way of reply, I first note that there's no requirement in Contradictory Christology that any other facet of the true theology - except that which follows directly from the contradiction who is Christ - be contradictory. Accordingly, McCall's scenario is indeed hypothetical, lest any reader should think otherwise. (And to be doubly clear: McCall nowhere suggests that Contradictory Christology requires further contradictions; he only rightly says that it may, for all that's been said so far.)

One question raised by McCall's scenario is whether it's possible. Clearly, the scenario is logically possible; but that's saying little. Moreover, as far as I know, the scenario is theologically possible. One might wonder, though, whether there's some 
physical impossibility that gets in the way. For example, it's physically (or cognitively or the like) impossible, I believe, to both accept and simultaneously reject the truth of some claim $A \cdot{ }^{15}$ It might be that being a priest requires that one accept some claim $A$ while being a non-priest requires that one reject the very same claim $A$. (I can't think of such a requirement, but for purposes of example imagine that the priesthood demands 'self-reflection' of its priests in such a way that the priest must, on pain of excommunication, accept that they themselves are priests - accept the claim I am a priest.) In this case, there's good reason to reject the physical (or cognitive or the like) possibility of McCall's scenario. Whether, then, McCall's scenario is possible in relevant respects turns on further details of the case.

Grant, for discussion, that the scenario is possible in relevant respects. Focus, as is McCall's intended target, on the upshot for the church and its obligations. (I say 'church' rather than 'Church' because McCall's scenario needn't be tied just to one particular tradition such as the Catholic Church.) What guidance should - can - be given by way of carrying out the obligations of the given contradiction concerning ordination? Truly, I do not know. I think that it's a very remote possibility - if, as we're assuming for discussion, a relevant possibility it be - that the church in its wisdom should arrive at such a position. After all, ordination has a very, very direct practical arm to it; and without having some sense of how the practical arm is to function in the final truth about ordination, it is unlikely that top-shelf church leaders will conclude that they've reached the final truth.

None of this is to say that moral dilemmas (even theologically driven moral dilemmas) - namely, moral obligations to do what you cannot relevantly possibly do - refute the truth of the moral claims that result in such dilemmas; they don't. My point about McCall's scenario is that it's at least implausible that the leaders would unanimously agree that the truth about such an important practical matter results in the obvious dilemma - namely, to both ordain and not ordain women. Does logical space allow it? Yes. Does the space of theological possibility allow it? We're assuming as much, at least for discussion. But does the given scenario reflect a likely practical issue for Contradictory Christianity - as the wider view of which Contradictory Christology is a part? I don't yet see it. ${ }^{16}$

\footnotetext{
${ }^{15}$ I'm not alone. Many theorists who either think that there are true glutty theories or think that there are true gappy theories or, like me, think that there are both sorts of such theories, reject that one can simultaneously accept and reject a claim $A$, even though the glut theorists require, for some $A$, acceptance of both $A$ and its negation $\neg A$ while the gap theorists require, for some $A$, rejection of both $A$ and its negation $\neg A$ (see Priest 2006; Field 2008; and Beall 2009).

${ }^{16}$ Acknowledgement: I am very, very grateful to Professor McCall for engaging with my work. What should be plain to all readers is that McCall's questions cut to the fundamental levels of both the theoretical viability and the in-practice viability of Contradictory Christology - a contradictory Christian theology in general. My hope is to move forward on both fronts, thanks to the generosity and richness of McCall's engagement. To Professor McCall: thank you. Truly.
} 


\section{Bibliography}

Beall, Jc. 2009. Spandrels of Truth. Oxford University Press.

. 2018. "The simple argument for subclassical logic." Philosophical Issues 28: $30-54$.

Beall, Jc and John P. Burgess. 2017. “Logic." In Oxford Bibliographies, edited by Duncan Pritchard. Oxford University Press.

Beall, Jc and Shay Logan. 2017. Logic: The Basics. Routledge.

Charry, Ellen T. 1997. By the Renewing of Your Minds: The Pastoral Function of Christian Doctrine. Oxford University Press.

Coakley, Sarah. 2002. "What Chalcedon solved and didn't solve." In The Incarnation, edited by Stephen T. Davis, SJ Daniel Kendall, and SJ Gerald O'Collins. Oxford University Press.

Field, Hartry. 2008. Saving Truth from Paradox. Oxford University Press.

Harman, Gilbert. 1973. "Rationality." In Reasoning, meaning, and mind. Oxford University Press. 1986. Change in View: Principles of Reasoning. MIT Press.

Martinich, A. P. 1978. "Logical operations." Journal of Religion 58: 169-181.

Pawl, Timothy. 2016. In Defense of Conciliar Christology: A Philosophical Essay. Oxford University Press.

Priest, Graham. 2006. In Contradiction. Oxford University Press. 2008. An Introduction to Non-Classical Logic. Cambridge University Press.

Ephraim Radner. 2016. Time and the Word: Figural Readings of the Christian Scriptures. William B. Eerdmans Publishing Co.

Rescher, Nicholas and Robert Brandom. 1979. The Logic of Inconsistency. Rowman and Littlefield.

Van Inwagen, Peter. 1988. "And yet they are not three gods but one god." In Philosophy and the Christian Faith, edited by Thomas V. Morris. University of Notre Dame Press. 